\title{
The Experience of COPD Patients in Lockdown Due to the COVID-19 Pandemic
}

This article was published in the following Dove Press journal:

International Journal of Chronic Obstructive Pulmonary Disease

\author{
Eulogio Pleguezuelos $\mathbb{D}^{1,2}$ \\ Amin Del Carmen (D) \\ Eva Moreno ${ }^{3}$ \\ Pilar Ortega ${ }^{4}$ \\ Xavier Vila $\mathbb{1}^{4}$ \\ Laura Ovejero ${ }^{4}$ \\ Mateu Serra-Prat ${ }^{5}$ \\ Elisabet Palomera $\mathbb{1 D}^{5}$ \\ Manuel Vicente Garnacho- \\ Castaño (iD ${ }^{6}$ \\ Eduardo Loeb ${ }^{7}$ \\ Georgina Farago (D) ${ }^{7}$ \\ Marc Miravitlles $\mathbb{D}^{7}$ \\ 'Physical Medicine and Rehabilitation \\ Department, Hospital de Mataró, \\ Barcelona, Spain; ${ }^{2}$ Department of \\ Experimental Science and Healthcare, \\ Faculty of Health Sciences, Universitat \\ Pompeu Fabra, Barcelona, Spain; ${ }^{3}$ Physical \\ Medicine and Rehabilitation Department, \\ Hospitalet General Hospital, L'Hospitalet \\ de Llobregat, Barcelona, Spain; \\ ${ }^{4}$ Pneumology Department, Hospital de \\ Mataró Mataró, Barcelona, Spain; \\ ${ }^{5}$ Research Unit, Consorci Sanitari del \\ Maresme, Barcelona, Spain; ${ }^{6}$ TGRI-AFIRS, \\ Department of Physical Activity and \\ Sports Science, School of Health \\ Sciences, Tecno Campus, Universitat \\ Pompeu Fabra, Barcelona, Spain; \\ ${ }^{7}$ Pneumology Department, Hospital \\ Universitari Vall d'Hebron, Vall d'Hebron \\ Institut de Recerca (VHIR), Vall d'Hebron \\ Barcelona Hospital Campus, CIBER de \\ Enfermedades Respiratorias (CIBERES), \\ Barcelona, Spain
}

Correspondence: Eulogio Pleguezuelos Hospital de Mataró, C/Cirera s/n 08302, Mataró, Barcelona, Spain

Tel +34 93.7417728

Fax +3493.7417717

Email epleguezuelos@csdm.cat
Purpose: On March 16, 2020, the Spanish government declared a state of alarm due to the rapid spread of coronavirus disease 2019 (COVID-19). Patients with chronic obstructive pulmonary disease (COPD) were restricted to remain confined at home, and medical visits were cancelled for 3 months. The impact of this lockdown on the manifestations of COPD and the quality-of-life of these patients has not been explored.

Patients and Methods: One hundred patients with COPD were interviewed by telephone from May 2-18, 2020. The interviews included questions about the lockdown, missed medical appointments, fears of the disease, possible COVID-19 infection, and exacerbations of COPD suffered during this period and their management. In addition, the COPD Assessment Test, the Hospital Anxiety and Depression, and the 5-Dimension Euro Qualityof-Life questionnaires were administered.

Results: Sixty-four (64\%) patients claimed to have strictly complied with the lockdown, and only $42(42 \%)$ stated they had left home at least once during lockdown. Only one patient (1\%) was hospitalized due to COVID-19, and 13 (13\%) patients presented an exacerbation of COPD self-managed at home with no admissions due to exacerbation of COPD during this period. A medical consultation or complementary test was cancelled in $90 \%$ of the patients, but $61 \%$ had a medical telephone visit with a high degree of satisfaction (mean 9.3/10). Most patients declared that their feeling regarding lung disease and general health was similar or even better during lockdown ( $82 \%$ and $81 \%$, respectively).

Conclusion: Our results indicate that in general lockdown had a low impact on COPD patients. Only one patient was affected by COVID-19, but moderate exacerbations of COPD were not infrequent. Although many medical visits and test were cancelled, patients were very satisfied with the medical telephone visits.

Keywords: COPD, lockdown, COVID-19

\section{Introduction}

Coronavirus disease 2019 (COVID-19) is caused by severe acute respiratory syndrome coronavirus type 2 (SARS-CoV-2) and was first identified in Wuhan, Hubei, China in December 2019. ${ }^{1}$ The disease spread very rapidly to the rest of China and later worldwide. A state of alarm was declared in Spain on March 16, 2020 with the aim of managing the emergency healthcare situation produced by COVID-19. Up to June 14, 2020, a total of 243,928 confirmed cases and 27,136 deaths by COVID-19 had been reported in Spain. ${ }^{2}$

COVID-19 more frequently affects the elderly and patients with chronic diseases such as hypertension and diabetes. The risk of COVID-19 in patients with COPD did not appear to be increased in the first series published, ${ }^{3,4}$ however, more 
recent studies from Western countries have demonstrated an increased risk of severe COVID-19 and increased mortality in patients with COPD. ${ }^{5,6}$

During the lockdown period there was a reduction in the number of patients attended in primary healthcare centers and emergency departments for exacerbations of other chronic diseases, including COPD. It has been hypothesized that the lack of social contact contributed to reduced exposure to other microorganisms, such as rhinoviruses, and that the improvement in air quality in large cities may also have contributed to the reduction in the frequency and severity of exacerbations. ${ }^{7}$ However, there are no epidemiological data about the frequency of exacerbations suffered during the lockdown that may have been self-treated at home.

In addition, there is no information about the possible impact of the lockdown on other aspects of the life of COPD patients, such as their fears, health status, physical activity, or the impact of lockdown on their planned medical care. In these circumstances, we designed a transversal observational study with the aim of evaluating the impact of lockdown due to COVID-19 on the quality-of-life and exacerbations in patients with severe COPD.

\section{Methods}

\section{Population}

Patients were consecutively recruited from the list of outpatient clinics of two general hospitals in the area of Barcelona (Spain). The inclusion criteria were: age older than 40 years and smokers or former smokers of at least 10 pack-years with a post-bronchodilator spirometry showing a forced expiratory volume in the first second/forced vital capacity $\left(\mathrm{FEV}_{1} / \mathrm{FVC}\right)<0.7$ and $\mathrm{FEV}_{1}$ (\% predicted) $<70 \%$. Exclusion criteria were: severe neurological disease, active oncological disease (because it could be a cause of scheduled/unscheduled visits and interfere with the results on the impact of lockdown on COPD), or the inability to understand the questions of the survey.

The Ethics and Research Committee of the Mataró Hospital approved the study including verbal informed consent for participation. The protocol was conducted in accordance with the principles of the Declaration of Helsinki, Good Clinical Practice, and the applicable and local regulatory requirements.

\section{Study Design}

This was a cross-sectional, observational study conducted though telephone interviews to patients with COPD.
Lockdown was enforced from March 15th until April 28th, and it was forbidden to leave the house except for emergencies and obtaining medical or food supplies. From April 28 to June 21 there was a period of progressive de-escalation of lockdown measures, with mandatory use of face masks on the street and in public places.

The patients were informed by telephone of the nature and purpose of the study, and they were asked to provide verbal informed consent. Interviews were conducted during the last 2 weeks of May, after the more restrictive lockdown was over, and covered the experience of the patients for 2 months. After the phone call, the electronic medical records were reviewed to collect information about lung function and clinical history including the history of exacerbations in the previous 12 months.

The grade of dyspnoea was evaluated using the modified Medical Research Council Dyspnoea Scale (mMRC). ${ }^{8}$ The COPD Assessment Test (CAT) was used to measure COPD-specific health-related quality-of-life (HRQoL). This questionnaire has eight ítems, with which a score from 0 to 40 is obtained, with a higher score indicating worse health. ${ }^{9}$ The Spanish version of the 5-Dimension Euro Quality-of-Life (EQ-5D) questionnaire was used to assess HRQoL. ${ }^{10}$ The EQ-5D is comprised of a descriptive system (utility score) and a visual analogscale (VAS), which asks the respondent to consider and rate their health "today". The VAS score is anchored at 100 (best imaginable health) and 0 (worst imaginable health) in this case, it was asked over the phone. The descriptive system enables the respondent to classify their health according to three levels in five dimensions: mobility, selfcare, usual activities, pain/discomfort, and anxiety/depression. The data may be used to represent a profile of health status or may be converted into a single summary index (EQ-5D index) by applying scores from a valuation set. Higher scores of the EQ-5D represent a more favorable health status.

The Hospital Anxiety and Depression (HAD) scale was used to examine mood disorders. This 14-item selfquestionnaire has two 7-item sub-scales for anxiety (HAD-A) and depression (HAD-D). A score of 11 or higher in either subscale is closely associated with the presence of the corresponding mood disorder. ${ }^{11}$

A survey was designed with the objective to obtain information about the lockdown period. Questions were related to verify the degree of compliance with lockdown and fears about COVID-19. We also asked about exacerbations of COPD and their treatment, the cancellation of 
clinical visits and tests, the satisfaction with telephone medical contacts, possible issues with medical supplies during lockdown, and physical activity during this period.

An exacerbation was defined as an increase in respiratory symptoms that required treatment with systemic corticosteroids or antibiotics or both. ${ }^{12}$

\section{Statistical Analysis}

Only descriptive statistics were performed. Data are reported as mean and standard deviations (SD) or number of observations and percentages.

\section{Results}

\section{Population Characteristics}

A total of 102 patients with COPD were screened, of whom two had died from cardiac events in the weeks prior to lockdown; the remaining 100 patients were the population of our study. The majority were men (76\%), with a mean age of 67.8 years ( $\mathrm{SD}=7.6$ years), and the mean FEV1(\%) was $46 \%$ ( $\mathrm{SD}=16.1 \%)$. The mean CAT score was $11.8(\mathrm{SD}=6.8)$, the mean HAD-D score was 2.2 $(\mathrm{SD}=3.6)$, and the HAD-A score was $4.0(\mathrm{SD}=4.1)$. In the 12 months prior to lockdown, $35 \%$ and $24 \%$ of patients had had an ambulatory exacerbation or hospital admission for an exacerbation, respectively (Table 1).

Sixty-four patients (64\%) strictly complied with lockdown, and 67 (67\%) declared to have been afraid of being infected by COVID-19. Only 42 (42\%) declared to have gone out on at least one occasion.

Only one patient (1\%) was admitted to hospital due to COVID-19, and no patient was admitted due to an exacerbation of COPD. The affected patient was a 72year-old male with $\mathrm{FEV} 1(\%)=55 \%$ and a history of hypertension and chronic renal failure. He presented with bilateral pneumonia, fever, and severe hypoxemia, and was hospitalized for 21 days, without the need for mechanical ventilation. In $90 \%$ of the patients a medical consultation or complementary test had been cancelled, but in $61 \%$ a telephone visit was carried out with a high degree of satisfaction (mean=9.3/10). A total of 13 patients $(13 \%)$ had had an exacerbation that required an antibiotic and/or corticosteroids, but they were treated on an outpatient basis. Only $18 \%$ and $19 \%$ felt worse from the point of view of their lung disease or their general health, respectively (Figure 1). The remainder of the information collected in the telephone interview is shown in Table 2.
Table I Patient Characteristics at Baseline

\begin{tabular}{|c|c|}
\hline$N=100$ & $\begin{array}{l}\text { N (\%) or Mean } \\
\text { (SD) }\end{array}$ \\
\hline Sex (\% women) & $24(24 \%)$ \\
\hline Age & $68(7.6)$ \\
\hline BMI $\left(\mathrm{Kg} / \mathrm{m}^{2}\right)$ & $26.8(5.1)$ \\
\hline FVC (L) & $2.7(0.8)$ \\
\hline FVC (\%) & $76.4(13.5)$ \\
\hline FEVI (L) & I.4 (0.5) \\
\hline FEVI (\%) & $46(16.1)$ \\
\hline FEVI/FVC (\%) & $48.7(13)$ \\
\hline GOLD stage I & $\mathrm{I}(\mathrm{I} \%)$ \\
\hline GOLD stage II & $38(38 \%)$ \\
\hline GOLD stage III & $40(40 \%)$ \\
\hline GOLD stage IV & $21(21 \%)$ \\
\hline Cough & $34(34 \%)$ \\
\hline Daily expectoration & $32(32 \%)$ \\
\hline Dyspnoea mMRC: & \\
\hline$\cdot 1$ & $25(25 \%)$ \\
\hline$\cdot$-II & $45(45 \%)$ \\
\hline • III & $27(27 \%)$ \\
\hline$\cdot \mathrm{IV}$ & $\mathrm{I}(\mathrm{l} \%)$ \\
\hline Rehabilitation in previous year & $68(68 \%)$ \\
\hline Outpatient exacerbations in previous year & $35(35 \%)$ \\
\hline Mean number of outpatient exacerbations & $0.49(0.77)$ \\
\hline Exacerbations with emergency care in previous year & $6(6 \%)$ \\
\hline Mean number of exacerbations with emergency care & $0.07(0.29)$ \\
\hline $\begin{array}{l}\text { Exacerbations with hospitalization (except ICU) } \\
\text { in previous year }\end{array}$ & $14(14 \%)$ \\
\hline $\begin{array}{l}\text { Mean number of exacerbations with } \\
\text { hospitalization (except ICU) }\end{array}$ & $0.18(0.48)$ \\
\hline Exacerbations with ICU stay in previous year & $4(4 \%)$ \\
\hline Mean number of exacerbations with ICU stay & $0.04(0.20)$ \\
\hline
\end{tabular}

Abbreviations: $\mathrm{N}$, number; $\mathrm{SD}$, standard deviation; $\mathrm{BMI}$, body mass index; mMRC, modified Medical Research Council Dyspnoea Scale; ICU, intensive care unit; FEVI, forced expiratory volume in the first second; FVC, forced vital capacity.

\section{Discussion}

The results of our study have shown a limited impact of the COVID-19 lockdown on patients with COPD. Scores in HRQoL questionnaires and in anxiety and depression were not worse than those observed in other populations of patients with COPD analyzed under normal circumstances. Although only one patient was hospitalised for COVID- 
A

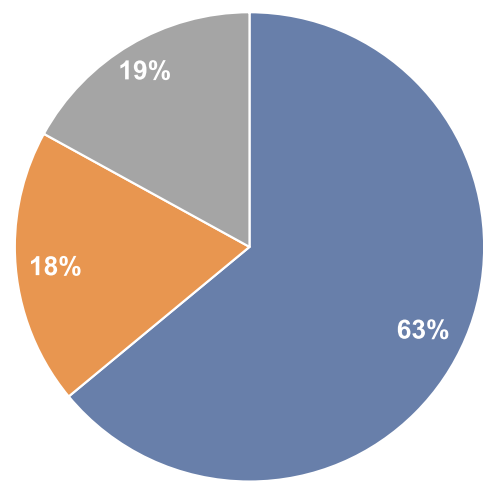

B

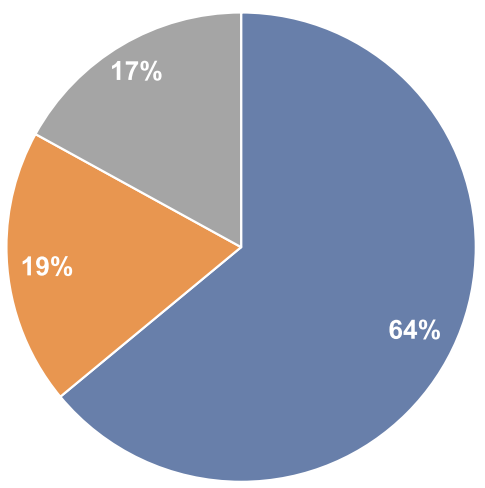

Same as before lockdown

Worse than before lockdown

Better than before lockdown

Figure I Perception of state of health during lockdown; (A) represents the results to the question "In relation to your lung disease (COPD), how did you feel during lockdown?"; (B) represents the results of the question "In relation to your health in general, how did you feel during lockdown?".

19 , up to $13 \%$ of patients experienced an exacerbation despite social isolation, and this was self-treated at home. The majority of patients had medical tests and/or clinical visits cancelled due to the lockdown, and those who experienced telephone medical visits were very satisfied with this type of interaction with the healthcare provider.

There is limited information about the impact of lockdown in patients with chronic diseases such as COPD. Although the sample size of our study does not allow analysis of the incidence of COVID-19 in COPD, we identified only one individual admitted for the disease. The risk of COVID-19 among patients with COPD has been controversial. The initial large reports of patients with COVID-19 showed an underrepresentation of patients with chronic respiratory diseases; namely COPD and asthma. $^{3,4}$ However, more recent studies from Europe and the US suggest an increased risk of COVID-19 associated with COPD. ${ }^{5-7}$

During the period of lockdown there has been a significant reduction in the number of patients attended in emergency departments for reasons other than COVID19 itself. In the field of COPD, this observation has been interpreted as a reduction in the incidence of exacerbations probably associated with the lockdown. It has been hypothesized that isolation at home may have prevented social contact that can be associated with transmission of viral agents which can trigger exacerbations. Another hypothesis suggests the improvement in air quality and the fact that fear of COVID-19 infection may have resulted in better compliance with hygienic measures and medications in this susceptible population of patients with
COPD. However, we have observed that $13 \%$ of our patients had an exacerbation that was self-treated at home, and was, therefore, unnoticed by the sanitary system. It is of note that our population basically consisted of severe COPD patients, with some frequent exacerbators, but it is also possible that due to the fears of COVID-19 patients may have been more sensitive to changes in symptoms and started treatment for exacerbation after a minimal increase in symptoms. In fact, the outcomes of these episodes, that were all limited without any other medical intervention (ie, clinical consultation, medical visit, or emergency visit), suggest that they may have been relatively mild, or treatment may have started early. Our results concur with those of Chan et al, ${ }^{13}$ who observed a significant reduction in the number of admissions for exacerbations of COPD in Hong Kong in the first 3 months of 2020 compared with previous years. The authors suggested that universal masking and social distancing during the COVID-19 pandemic contributed to preventing respiratory tract infections.

Approximately two thirds of our patients were fearful of COVID-19, and one third were afraid of dying. This may explain the high level of compliance with the lockdown. Up to $64 \%$ of patients strictly complied with lockdown, and 58\% never left home during this period, not even for the reasons allowed. One of these reasons was to attend medical appointments, but the majority of non-urgent medical appointments had been cancelled in our area during the lockdown period. Thus, diagnostic tests or medical visits had been cancelled during lockdown in $90 \%$ of our patients. It is still too early to 
Table 2 Evaluation During Lockdown

\begin{tabular}{|c|c|}
\hline$N=100$ & $\mathbf{N}(\%)$ or Mean (SD) \\
\hline \multicolumn{2}{|l|}{ Questionnaires } \\
\hline CAT & II.6 (6.8) \\
\hline EuroQ5D (index) & $0.81(0.28)$ \\
\hline EuroQ5D (Visual Analog Scale) & $64.4(18.1)$ \\
\hline HAD depression & $2.2(3.6)$ \\
\hline HAD anxiety & $4(4.1)$ \\
\hline \multicolumn{2}{|l|}{ Targeted questions } \\
\hline Have you completely complied wth the lockdown caused by COVID-19? & $64(64 \%)$ \\
\hline Have you ever been out on the street during the lockdown period? & $42(42 \%)$ \\
\hline Have you been admitted to hospital during lockdown? & I ( $(1 \%)$ \\
\hline If yes, was it due to COVID-19 infection? & I ( $(\%)$ \\
\hline Have any clinical visits or tests been cancelled during the lockdown? & $90(90 \%)$ \\
\hline If yes, how many? & $2(1.4)$ \\
\hline Have you had a medical visit by phone? & $61(61 \%)$ \\
\hline If yes, what was your level of satisfaction with the telephone visit? (scale 0-10) & $9.3(1.2)$ \\
\hline Have you done physical activity at home during lockdown? & $72(72 \%)$ \\
\hline Have you had any exacerbations during the lockdown period? & $13(13 \%)$ \\
\hline Did you need to take an antibiotic during lockdown? & $13(13 \%)$ \\
\hline Did you have to take oral corticosteroids during lockdown? & $12(12 \%)$ \\
\hline Did you have problems in the supply of medication during lockdown? & $3(3 \%)$ \\
\hline Have you been afraid of getting COVID-19? & $67(67 \%)$ \\
\hline Have you been afraid of death during the lockdown period? & $37(37 \%)$ \\
\hline \multicolumn{2}{|l|}{ In relation to your lung disease (COPD), how did you feel during lockdown? } \\
\hline a. Same as before lockdown & $63(63 \%)$ \\
\hline b. Worse than before lockdown & $18(18 \%)$ \\
\hline c. Better than before lockdown & $19(19 \%)$ \\
\hline \multicolumn{2}{|l|}{ In relation to your health in general, how did you feel during the lockdown? } \\
\hline a. Same as before lockdown & $64(64 \%)$ \\
\hline b. Worse than before lockdown & $19(19 \%)$ \\
\hline c. Better than before lockdown & $17(17 \%)$ \\
\hline
\end{tabular}

Abbreviations: SD, standard deviation; CAT, COPD Assessment Test; HAD, Hospital Anxiety and Depression scale; COVID-19, Coronavirus infectious disease 2019.

understand the real impact (beyond the increase in the waiting lists) of cancelling or delaying many medical interventions during this period, not only on patients with COPD but also on chronic patients in general. In an attempt to adapt to the new circumstances, our centers started a program of telephone follow-up visits for patients with COPD. It is encouraging to see that among the $61 \%$ of patients who had a telephone medical visit, the level of satisfaction was very good, with a mean satisfaction score of 9.3 over 10 . It is probably too early to assess the satisfaction of patients and healthcare providers with this new type of medical visit. Both patients and healthcare providers still see it as provisional while awaiting a return to the usual activities. Furthermore, the impact in terms of possible medical errors due to lack of physical medical attention is an aspect that will require careful consideration, if this new model is here to stay. ${ }^{14,15}$

Interestingly, we observed that the CAT, EQ-5D, and HADs scores were even better to those observed in COPD patients from our area obtained outside the lockdown period.

The mean CAT score was 11.6, compared with 21.8 in a recent study on 684 Spanish COPD patients, ${ }^{16}$ and the mean EQ-5D index was 0.81, compared with 0.67 observed in a large study on 6198 COPD patients. ${ }^{17}$ It must be taken into account that, due to the characteristics of our study, these questionnaires were not selfadministered, but rather were administered by an interviewer by phone, and this may have influenced the results. 
However, in agreement with these results, $82 \%$ and $81 \%$ of patients declared that their COPD and their general health were the same or better than before the lockdown, respectively.

A significant group of our patients had followed a pulmonary rehabilitation program, and it is of note that up to $72 \%$ continued to do some kind of physical activity at home during lockdown. We are implementing a program of telerehabilitation for patients with COPD in order to fulfill the requirements of pulmonary rehabilitation in this new post-COVID period. ${ }^{18,19}$

The lockdown due to the COVID-19 pandemic has changed the lives of our patients with COPD. Their medical visits have been cancelled and a new type of medical visits and rehabilitation programs are being implemented. Apparently, COPD patients have adapted quite well to this period of lockdown, but the new ways of delivering medical attention must be carefully evaluated in the future. ${ }^{20}$

In summary, our results showed that lockdown had a low impact on COPD patients. Only one patient was affected by COVID-19, but moderate exacerbations of COPD were not infrequent. Although many medical visits and tests were cancelled, patients were very satisfied with the medical telephone visits.

\section{Disclosure}

Marc Miravitlles has received speaker fees from AstraZeneca, Boehringer Ingelheim, Chiesi, Cipla, Menarini, Rovi, Bial, Sandoz, Zambon, CSL Behring, Grifols, and Novartis, consulting fees from AstraZeneca, Boehringer Ingelheim, Chiesi, GlaxoSmithKline, Bial, Gebro Pharma, Kamada, CSL Behring, Laboratorios Esteve, Ferrer, Mereo Biopharma, Verona Pharma, TEVA, Spin Therapeutics, pH Pharma, Novartis, Sanofi, and Grifols, and research grants from GlaxoSmithKline and Grifols, outside the submitted work, and reports no other potential conflicts of interest in this work. The remaining authors have no conflicts of interest to disclose for this work.

\section{References}

1. Huang C, Wang Y, Li X, et al. Clinical features of patients infected with 2019 Novel Coronavirus in Wuhan, China. Lancet. 2020;395 (10223):497-506. doi:10.1016/S0140-6736(20)30183-5.

2. Available from: https://www.mscbs.gob.es/en/profesionales/ saludPublica/ccayes/alertas Actual/nCov-China/documentos/ Actualizacion_136_COVID-19.pdf. Accessed June 16, 2020.

3. Zhou F, Yu T, Du R, et al. Clinical course and risk factors for mortality of adult inpatients with COVID-19 in Wuhan, China: a retrospective cohort study. Lancet. 2020;395(10229):1054-1062. doi:10.1016/ S0140-6736(20)30566-3
4. Grasselli G, Zangrillo A, Zanella A, et al. Baseline characteristics and outcomes of 1591 patients infected with SARS-CoV-2 admitted to ICUs of the Lombardy Region, Italy. JAMA. 2020;323 (16):1574-1581. doi:10.1001/jama.2020.5394

5. Alqahtani J, Oyelade T, Aldhahir A, et al. Prevalence, severity and mortality associated with COPD and smoking in patients with COVID-19: a rapid systematic review and meta-analysis. PLoS One. 2020;15(5):e0233147. doi:10.1371/journal.pone.0233147

6. Lippi G, Henry BM. Chronic obstructive pulmonary disease is associated with severe coronavirus disease 2019 (COVID-19). Respir Med. 2020;167:105941. doi:10.1016/j.rmed.2020.105941

7. Gonçalves JMF, Golpe R, García-Talavera I. Chronic obstructive pulmonary disease and SARS-CoV-2 infection. What do we know so far? Arch Bronconeumol. 2020 Jul;56 Suppl 2:5-6. doi:10.1016/j. arbres.2020.04.016

8. Bestall JC, Paul EA, Garrod R, Garnham R, Jones PW, Wedzicha JA. Usefulness of the Medical Research Council (MRC) dyspnoea scale as a measure of disability in patients with chronic obstructive pulmonary disease. Thorax. 1999;54(7):581-586. doi:10.1136/ thx.54.7.581

9. Jones PW, Harding G, Berry P, Wiklund I, Chen W-H, Kline Leidy N. Development and first validation of the COPD assessment test. Eur Respir J. 2009;34:648-654. doi:10.1183/09031936.00102509

10. Badia X, Roset M, Montserrat S, Herdman M, Segura A. La versión española del EUROQoL: descripción y aplicaciones. Med Clin (Barc). 1999;112:79-85.

11. Herrero MJ, Blanch J, Peri JM, De Pablo J, Pintor L, Bulbena A. A validation study of the hospital anxiety and depression scale (HADS) in a Spanish population. Gen Hosp Psychiatry. 2003;25:277-283. doi:10.1016/S0163-8343(03)00043-4

12. Wedzicha JA, Miravitlles M, Hurst JR, et al. Management of COPD exacerbations: an European Respiratory Society/American Thoracic Society (ERS/ATS) guideline. Eur Respir J. 2017;49:1600791. doi:10.1183/13993003.00791-2016

13. Chan KPF, Ma TF, Kwok WC, et al. Significant reduction in hospital admissions for acute exacerbation of chronic obstructive pulmonary disease in Hong Kong during coronavirus disease 2019 pandemic. Respir Med. 2020;171:106085. doi:10.1016/j.rmed.2020.106085

14. Barreiro E, Jiménez C, García de Pedro J, Ramírez Prieto MT. COVID-19 and XXI century pulmonology: challenge or opportunity? Arch Bronconeumol. 2020;56(7):411-412. doi:10.1016/ j.arbr.2020.05.002

15. Alcázar-Navarrete B, Molina Paris J, Martin Sanchez FJ. Management and follow up of respiratory patients in the post-COVID-19 era: are we ready yet? Arch Bronconeumol. 2020 Oct;56(10):685-686. doi:10.1016/j.arbr.2020.08.005

16. Miravitlles M, Molina J, Quintano JA, Campuzano A, Pérez J, Roncero C; DEPREPOC study investigators. Depressive status explains a significant amount of the variance in COPD Assessment Test (CAT) scores. Int $J$ Chron Obstruct Pulmon Dis. 2018;13:823-831. doi:10.2147/COPD.S154791

17. Esquinas C, Ramon MA, Nuñez A, et al. Correlation between disease severity factors and EQ-5D utilities in chronic obstructive pulmonary disease. Qual Life Res. 2020;29(3):607-617. doi:10.1007/s11136019-02340-4

18. Pleguezuelos E, Guirao L, Moreno E, et al. Safety of rehabilitation program for COPD patients. Arch Bronconeumol. 2018;54 (2):111-112. doi:10.1016/j.arbres.2017.06.012

19. Pleguezuelos E, Gimeno-Santos E, Hernández C, et al. Recommendations on non-pharmacological treatment in chronic obstructive pulmonary disease from the Spanish COPD guidelines (GesEPOC 2017). Arch Bronconeumol. 2018;54(11):568-575. doi:10.1016/j.arbres.2018.06.001

20. Leung JM, Niikura M, Yang CWT, Sin DD. COVID-19 and COPD. Eur Respir J. 2020;56:2002108. doi:10.1183/13993003.02108-2020 


\section{Publish your work in this journal}

The International Journal of COPD is an international, peer-reviewed journal of therapeutics and pharmacology focusing on concise rapid reporting of clinical studies and reviews in COPD. Special focus is given to the pathophysiological processes underlying the disease, intervention programs, patient focused education, and self management

protocols. This journal is indexed on PubMed Central, MedLine and CAS. The manuscript management system is completely online and includes a very quick and fair peer-review system, which is all easy to use. Visit http://www.dovepress.com/testimonials.php to read real quotes from published authors.

Submit your manuscript here: https://www.dovepress.com/international-journal-of-chronic-obstructive-pulmonary-disease-journal 